\title{
Evaluating the spectrum of histomorphological patterns on endoscopic biopsy in patients with upper gastrointestinal tract disorders
}

\author{
Theresa J. ${ }^{1}$, Lavanya M. ${ }^{2}$, Rakesh J. ${ }^{3 *}$, Basha K. ${ }^{4}$ \\ DOI: https://doi.org/10.17511/jopm.2020.i01.01 \\ 1 J. Margaret Theresa, Assistant Professor, Department of Pathology, Sri Venkateshwaraa Medical College Hospital and Research Centre, \\ Pondicherry, Puducherry, India. \\ 2 Lavanya M., Associate Professor, Department of Pathology, Sri Venkateshwaraa Medical College Hospital and Research Centre, \\ Pondicherry, Puducherry, India. \\ 3* J. Gerard Rakesh, Associate Professor, Department of Pathology, Sri Venkateshwaraa Medical College Hospital and Research Centre, \\ Pondicherry, Puducherry, India. \\ ${ }^{4}$ K. Sultan Basha, 2nd year MBBS Student, Department of Microbiology, Sri Venkateshwaraa Medical College Hospital and Research Centre, \\ Pondicherry, Puducherry, India.
}

Introduction: The upper gastrointestinal tract (UGT) disorders are more common complaints in clinical practice and have got high degree of mortality and morbidity. Many different types of lesions can affect the upper gastrointestinal tract and can be classified as congenital anomalies, infections, inflammation and neoplastic lesions. Material and Methods: A total of 152 cases of upper gastrointestinal tract biopsies are included in this study, out of which 113 cases were gastric biopsies, 22 cases were esophageal biopsies and the remaining 17 cases were duodenal biopsies. Present study was carried out in the Department of Pathology at Sri Venkateshwaraa Medical College Hospital and Research Centre, Puducherry for a period of one year between March 2018 and February 2019. All the biopsies were performed using fiberoptic endoscopy. Results: It is reported among 152 cases of UGT biopsies 137 were non-neoplastic lesions and 15 were neoplastic. Commonly affected age group was 31-40 years followed by 41 to 50 years. As per the present study, males were affected more predominantly than females. Out of the 22 cases from esophageal biopsies, 16 cases showed non-neoplastic lesions and 6 were neoplastic.

Keywords: Gastrointestinal tract disorders, Endoscopic Biopsy, Histomorphological examination, Helicobacter pylori, Malignant neoplasms and Squamous cell carcinoma

Corresponding Author

J. Gerard Rakesh, Associate Professor, Department of Pathology, Sri Venkateshwaraa Medical College Hospital and Research Centre, Pondicherry, Puducherry, India.

Email: drgerie@gmail.com
How to Cite this Article

Theresa MJ, Lavanya M, Gerard RJ, Sultan BK. Evaluating the spectrum of histomorphological patterns on endoscopic biopsy in patients with upper gastrointestinal tract disorders. Trop J Pathol Microbiol. 2019;6(1):1-8.

Available From

https://pathology.medresearch.in/index.php/jopm/ar ticle/view/401
To Browse

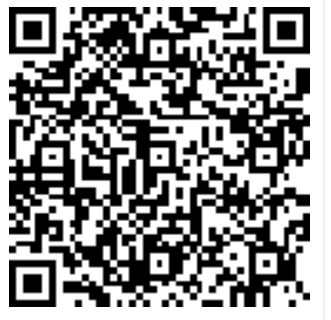

Manuscript Received 10-12-2019

Conflict of Interest No

Review Round 1
20-12-2019
Funding
Nil

$\begin{gathered}\text { Review Round } 2 \\ \text { 24-12-2019 }\end{gathered}$
Ethical Approval
Yes

Review Round 2 Yes
Review Round 3

Accepted 28-12-2019

Plagiarism X-checker $14 \%$

(C) 2019 by J. Margaret Theresa, Lavanya M., J. Gerard Rakesh, K. Sultan Basha and Published by Siddharth Health Research and Social Welfare Society. This is an Open Access article licensed under a Creative Commons Attribution 4.0 International icense https://creativecommons.org/licenses/by/4.0/ unported [CC BY 4.0]. 


\section{Introduction}

The upper gastrointestinal tract disorders are the common complaints in the clinical practice and has got high degree of mortality and morbidity [1]. The upper gastrointestinal tract comprises of oral cavity, esophagus, stomach and duodenum. Several lesions can affect the UGT which are broadly classified into congenital anomalies, infections, inflammation, benign and malignant neoplasms [2].

To visualize and to get the specimen from the gastrointestinal tract a flexible, fiberoptic endoscopy is used. Endoscopic biopsy in combination with histopathological examination plays an important role in the early diagnosis of esophago-gastroduodenal lesions [3].

Though endoscopic biopsies are invasive procedures, it is considered to be the gold standard for determining UGT lesions. It also helps the clinician and pathologist to correlate with the clinical data [4].

Endoscopic biopsy coupled with histopathological examination in patients with gastrointestinal disorders help us to provide early detection of precancerous and cancerous lesions and timely management of the disease [5].

Endoscopic biopsies are not only used for the early diagnosis of lesion but also for monitoring the course of disease, its extent, response to therapy and early detection of complications $[6,7]$.

Classification of gastritis based on Sydney system, emphasizes the importance of morphological, etiological and topographical informations. This system was revised in the year 1994 at Houston gastritis workshop [8].

The updated Sydney system explains the chronic inflammation, activity, atrophy, intestinal metaplasia and histological severity of $H$. Pylori density [9].

H. Pylori has been confirmed to be the causative organism for the development of gastric carcinoma. It is more frequently found within the mucous layer and in the gastric pits, which is often visible in Hematoxylin and Eosin stain. Special stains like Giemsa, Warthin starry stain can help us in easy demonstration of H.pylori $[10,11]$.

According to National Cancer Registry - Carcinoma of stomach and esophagus are seen commonly in males. Early detection of these cancers through endoscopic biopsies, can provide appropriate
Treatment and have great impact on the survival of the patients $[12,13]$.

Therefore, this study is planned to evaluate the histomorphological patterns of upper gastrointestinal disorders on endoscopic biopsy and to correlate various histomorphological lesions of upper gastrointestinal tract with respect to age, sex and with other clinical details.

\section{Materials and Methods}

Type of study: Prospective, observational and descriptive.

Place of study: Department of Pathology at Sri Venkateshwaraa Medical College Hospital and Research Centre, Pondicherry.

Duration of study: One year between March 2018 and February 2019.

Sample collection: The present study included upper gastrointestinal tract biopsies received in the department of pathology. The biopsies were processed and section cutting were carried out. Those sections were stained by Hematoxylin and Eosin. Special stains such as Giemsa, Warthin starry stains were also done whenever indicated. The stained slides were examined and histomorphological patterns were studied.

All the relevant data such as age, gender, duration of symptoms of the patients were also obtained and documented. Other routine investigation results and radiological examination like $\mathrm{X}$-ray and ultrasound reports of the patients were also recorded.

Inclusion criteria: All the upper gastrointestinal endoscopic biopsies, which included the lesions from esophagus, stomach and up to second part of duodenum.

Exclusion criteria: Patients presenting lesion in the oral cavity, pharynx and beyond the second part of duodenum.

\section{Results}

In the present study, the frequency of distribution of histomorphological patterns on endoscopic biopsy in patients with upper gastrointestinal tract disorders was analyzed.

Among the 152 cases of UGT biopsies, 113 biopsies were from stomach (74\%). A total of 22 biopsies were from esophagus which showed $(15 \%)$ and the 
Remaining 17 biopsies were from duodenum (11\%) showed in Figure 1.

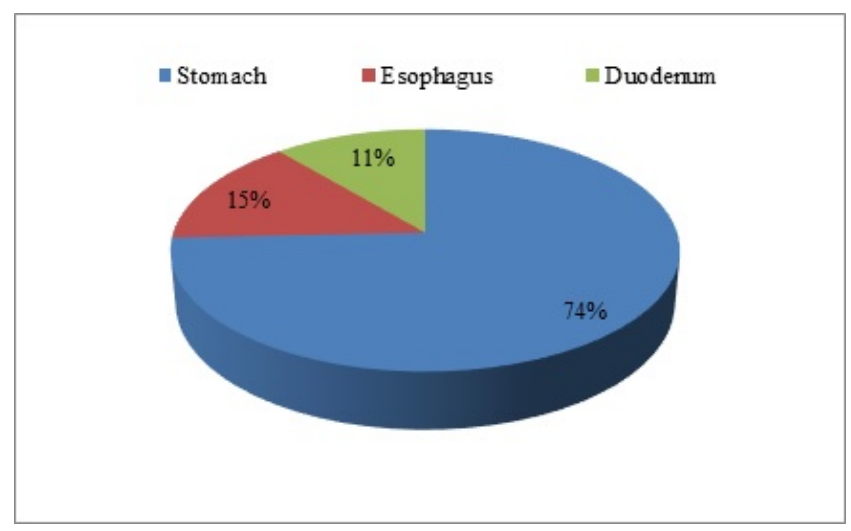

\section{Fig-1: Site wise distribution of UGT biopsies.}

Among the 152 cases of upper endoscopic biopsies 137 were non-neoplastic ( $90 \%)$ and the other15were neoplastic lesions (10\%) as represented in Figure 2.

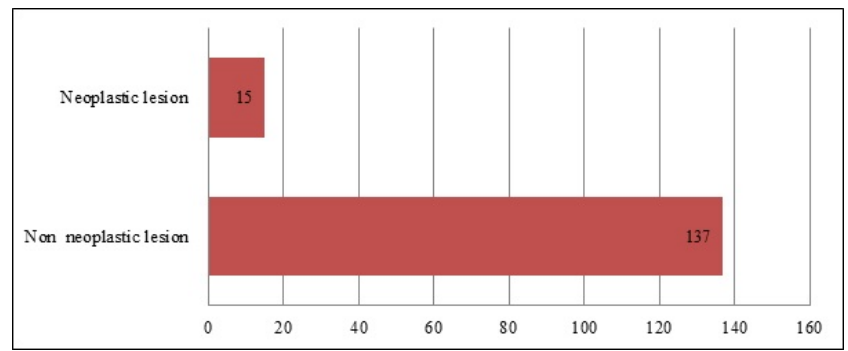

Fig-2: Frequency of distribution of neoplastic and non-neoplastic lesions.

As per the gender concern, out of the total 152 cases of UGT biopsies 87 were from males and the remaining 65 were from females. Distribution of UGT lesions in esophagus, stomach and duodenum among males and females as represented in Figure 3.

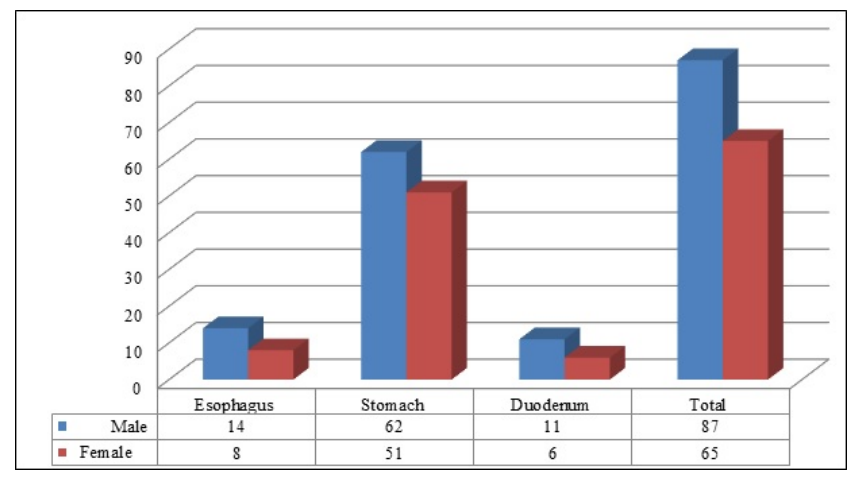

Fig-3: Frequency of distribution of lesions in male and female.

The study result in relevance to the age groups revealed that, among the 152 cases of upper gastrointestinal biopsies, the commonly affected age group was 31-40 years followed by 41 to 50 years.
The youngest age included in the study was 16 years female with esophagitis. The elderly age included in the study was 72 years male with gastric carcinoma as represented in Table 1.

Table-1: Frequency of distribution of lesion according to age.

\begin{tabular}{|l|l|l|l|}
\hline \multicolumn{1}{|c|}{ Age } & Esophagus & Stomach & \multicolumn{1}{c|}{ Duodenum } \\
\hline$<20$ & 1 & - & - \\
\hline $21-30$ & 5 & 6 & 5 \\
\hline $31-40$ & 6 & 56 & 10 \\
\hline $41-50$ & 4 & 32 & 2 \\
\hline $51-60$ & 4 & 8 & - \\
\hline $61-70$ & 2 & 3 & - \\
\hline $71-80$ & - & 8 & - \\
\hline Total & 22 & 113 & 17 \\
\hline
\end{tabular}

Common non-neoplastic lesion among the esophageal biopsies were chronic non-specific esophagitis, followed by esophageal ulcer.

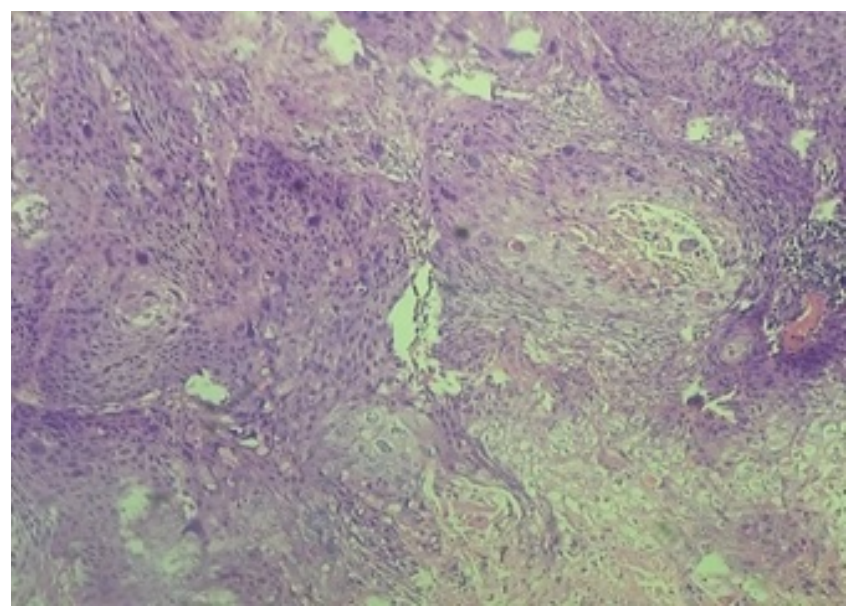

Fig-4: Microscopic feature of squamous cell carcinoma of esophagus, Haematoxylin and Eosin stain (10X).

Table-2: Frequency of distribution of esophageal lesion

\begin{tabular}{|c|c|c|}
\hline Histopathological Diagnosis & No.of Cases & Percentage \\
\hline \multicolumn{3}{|l|}{ Non-neoplastic lesions } \\
\hline Chronic non-specific esophagitis & 9 & 40.9 \\
\hline Esophageal ulcer & 3 & 13.63 \\
\hline Esophageal candidiasis & 1 & 4.54 \\
\hline Barrets esophagus & 3 & 13.63 \\
\hline \multicolumn{3}{|l|}{ Neoplastic lesions } \\
\hline Carcinoma in situ & 2 & 9.09 \\
\hline Squamous cell carcinoma & 4 & 18.18 \\
\hline Total & 22 & 100 \\
\hline
\end{tabular}

The common neoplastic lesion observed was squamous cell carcinoma (Figure 4) and there are three cases of barrets esophagus was also observed 
In this study as represented in Table 2.

Among 113 cases of gastric biopsies 104 were nonneoplastic and 9 were neoplastic lesions. Similarly, among the non-neoplastic lesions chronic superficial gastritis observed in 24 cases followed by chronic active gastritis in 22 cases and an equal number of cases in chronic superficial gastritis with intestinal metaplasia (Figure 5). Among the neoplastic lesion's adenocarcinoma of stomach (Figure 6) was the commonly observed lesions shown in Table 3.

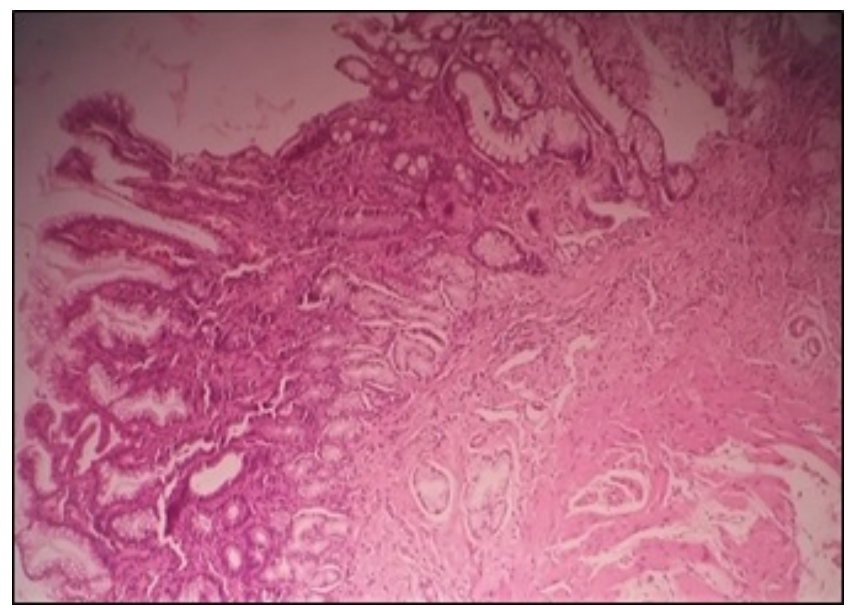

Fig-5: Chronic superficial gastritis with intestinal metaplasia, Haematoxylin and Eosin stain (10X).

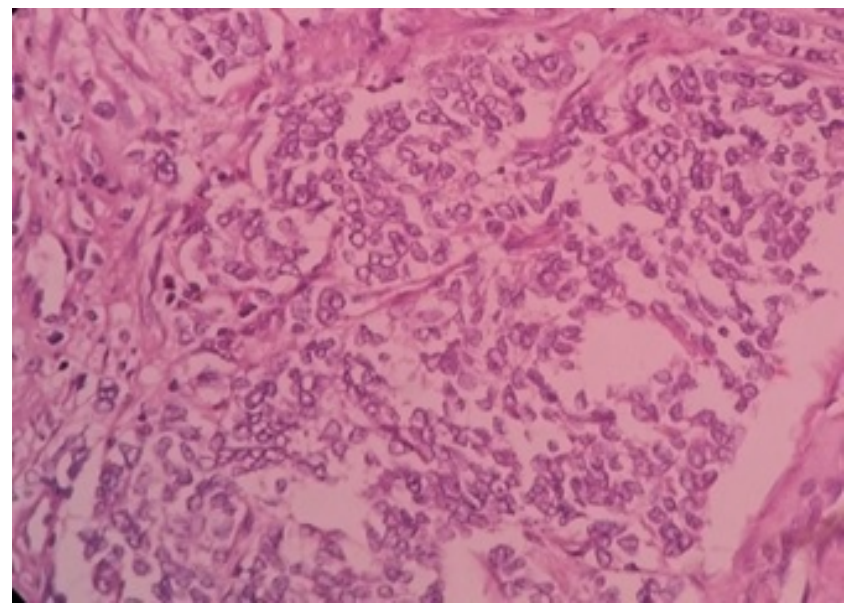

Fig -6: Adenocarcinoma of stomach, Haematoxylin and Eosin stain(40X).

Table-3: Frequency of distribution of gastric lesion

\begin{tabular}{|c|c|c|}
\hline Histopathological diagnosis & No. of Cases & $\%$ \\
\hline \multicolumn{3}{|l|}{ Non- neoplastic lesions } \\
\hline Chronic superficial gastritis & 24 & 21.23 \\
\hline Chronic active gastritis & 22 & 19.43 \\
\hline Chronic superficial gastritis with intestinal metaplasia & 22 & 19.46 \\
\hline H.pylori associated gastritis & 21 & 18.58 \\
\hline
\end{tabular}

\begin{tabular}{|l|l|l|}
\hline Eosinophilic gastritis & 3 & 2.65 \\
\hline Gastric ulcer & 8 & 7.17 \\
\hline Gastric polyp & 4 & 3.53 \\
\hline Neoplastic lesions & 4 & \multicolumn{2}{l|}{} \\
\hline Gastricintraepithelial neoplasm & 3 & 2.65 \\
\hline Adenocarcinoma & 6 & 5.30 \\
\hline Total & 113 & 100 \\
\hline
\end{tabular}

Among the17 duodenal biopsies obtained, on analysis, all of them were found as non-neoplastic. The lesion observed was chronic nonspecific duodenitis as represented in Table 4.

Table-4: Frequency of distribution of duodenal lesion

\begin{tabular}{|c|c|c|}
\hline Histopathological diagnosis & No. of cases & Percentage \\
\hline \multicolumn{3}{|l|}{ Non-neoplastic lesions } \\
\hline Chronic non-specific duodenitis & 8 & 47.06 \\
\hline Duodenal ulcer & 6 & 35.29 \\
\hline Duodenal polyp & 3 & 17.65 \\
\hline Total & 17 & 100 \\
\hline
\end{tabular}

\section{Discussion}

Various lesions can affect the upper gastrointestinal tract and may due to congenital anomalies, infections, inflammation, polyps, benign and malignant neoplasms. According to national cancer registry the incidence of gastric and esophageal cancers is gradually increasing according to the Globocan $[14,15]$.

Its worldwide incidence is believed to be increasing and are associated with poor prognosis. Hence there is an essential need to detect the lesion at an early stage.

Endoscopy helps in visualizing the gastrointestinal mucosa. The biopsies taken during the procedure help in confirming the diagnosis and to categorize them. Before the advent of endoscopic biopsy direct access to the lesions of gastrointestinal tract for the confirmation of the diagnosis was difficult, this resulted in difficulty in contemplating adequate and appropriate surgery [16].

Endoscopic biopsy also played an important role in the early detection of malignancies. Biopsies obtained under direct vision, through a working endoscopic channel in greater number of biopsies from a suspected malignancy increases the diagnostic yield [17] and may be useful in making therapeutic decisions to improve the prognosis of the patients. 
H.pylori are found to be the frequent organism within the muscular layer and within the gastric pits. The organisms are visible in Hematoxylin and Eosin stain. In Hematoxylin and eosin staining sensitivity and specificity as $69-93 \%$ and $87-90$ respectively which are also more easily visualized in special stains like Giemsa and Warthins starry stains.

Particularly it is useful in detecting the bacilli when they are in small number. The specificity can be improved $90-100 \%$ by using special stains such as modified Giemsa stain, Warthin -Starry silver stain $[18,19]$. Electron microscopic examination showed that the bacilli are adherent to the surface epithelium $[20,21]$. It has been confirmed that the development of gastric cancer arises from background of $H$. pylori infection $[22,23]$.

Sydney system of classification for gastritis emphasizes the importance of morphological, topographical and etiological information about the lesion. The revised Sydney system which was held in Houston gastric workshop also defined the histological severity of $H$. Pylori density, inflammation, activity, atrophy and intestinal metaplasia.

The introduction of the Sydney system made it possible to grade histological parameters, identify topographical distribution and etio-pathogenesis of the gastritis. However still non-standard histological reporting formats are widely used for gastritis which make it difficult to identify the patients for clinicoendoscopic surveillance. Additionally, there is no validated test to quantify the density of $H$. Pylori infection [24].

In the present study, among 152 cases of upper gastrointestinal tract biopsies, more number of cases were received from stomach $113(74.34 \%)$, followed by esophagus 22 (14.47\%) and duodenum $17(11.19 \%)$. Similar result was observed in a study conducted by Bilal A Sheikh [25], wherein the site wise distribution of endoscopic biopsies showed that in stomach 127 (64.8\%), oesophagus 50 (25.51\%), gastro-esophageal junction $15 \quad(7.65 \%)$ and duodenum 4 (2.04\%).

In the case of neoplastic verses non neoplastic lesions in the present study report showed that out of 152 cases 137 (90.13\%) were non neoplastic lesions and 15 (9.87\%) were neoplastic lesions.

However, yet another study by Khatib $W$ et al [26] showed a slightly altered report in which the non-neoplastic lesions observed in $75.29 \%$ of case
Cases and the neoplastic lesions were seen in $24.71 \%$ of cases. The variation in the results may due to personal, nutritional and environmental factors of the individuals.

Age and sex wise distribution of lesions of the present study reports showed that the most commonly affected age group was 31-40 years followed by $41-50$ years. Our result is slightly contradict with the studies carried out by Shepherd NA [27].

Shennak M M et al [28] and Islam SM et al [29], Wherein they studied the endoscopic biopsy for gastrointestinal tract lesions in which the commonly affected age group was between fifth and sixth decades of life.

As per the present study, among the 152 cases of upper endoscopic biopsies, 87(57.20 \%) were males and $65(42.80 \%)$ were female. Males were the predominant population affected with UGT disorders when compared to female [30].

Similar results were observed by Nwafor CC et al [30], who studied on 190 case of gastrointestinal biopsies showed the result $58 \%$ with male predominance and remaining $41 \%$ females were affected. The age related difference could be due to varied exposure to the risk factors among the different age groups.

Among the 22 esophageal biopsies received 16 $(72 \%)$ of them showed non neoplastic lesions and the remaining $6(28 \%)$ were neoplastic lesions. The present study report showed that the common non neoplastic lesion was chronic nonspecific esophagitis, followed by esophageal ulcer. It was also observed that squamous cell carcinoma was the most frequently reported neoplastic lesion.

A study conducted by Rosy Khandelia et al [31] also showed similar findings in that it was observed out of 115 upper gastrointestinal biopsies, 48 (41.74\%) were from esophagus in origin and the most common non neoplastic lesion was Chronic nonspecific esophagitis. The study also confirmed that the squamous cell carcinoma of esophagus was the common neoplastic lesion.

In the case of gastric biopsies 113 as per the present study 104 (92\%) were non neoplastic and only $9(8 \%)$ cases were neoplastic, which is similar to that of the study result of Syed Imtiyaz et al [32] report showed that $57.4 \%$ of cases were non neoplastic and $42.6 \%$ were neoplastic. 
In the present study, among the non-neoplastic lesions it was observed that chronic superficial gastritis, $24(21.23 \%)$ followed by chronic active gastritis $22(19.43 \%)$, chronic superficial gastritis with intestinal metaplasia $22(19.43 \%)$ and 21 cases $(18.58 \%)$ were $H$. Pylori associated gastritis. The common neoplastic lesion observed in the present study is adenocarcinoma of stomach.

The study by Rupendra Thapa et al [33] stated that the common non-neoplastic lesion observed was mild chronic gastritis $22(27.5 \%)$ followed by

Chronic active gastritis 15 (18.75\%) while H.pylori was present in $13(16.25 \%)$ and common neoplastic lesion were adenocarcinoma which correlated with the present study report.

Among the 17 cases of duodenal biopsies in the present study result showed that all 17 were non neoplastic and the commonly observed condition was chronic nonspecific duodenitis.

This result is in correlation with the study result of previous study [34].

\section{Conclusion}

The study report concluded that the upper gastrointestinal biopsies, on examination in combination with histopathological studies provides a useful information in the determination of overall extent of mucosal architecture and the use of special stains like Giemsa, Warthin starry stains made it easy to demonstrate $H$. Pylori in the gastric pits and mucous layer.

All the biopsies were performed using fiberoptic endoscopy which plays an important role in the improved visualization and accuracy in the UGT lesions could be directly inspected and helps to evaluate the various clinical conditions at the early stage.

Further the early result favors to correlate various disorders in correspondence to the clinical parameters and also the neoplastic and nonneoplastic lesions. Use of fiberoptic endoscopic biopsy helps to detect the site and distribution of the benign and malignant lesions.

Early and more specific diagnosis help for the management of disease which intern reduces the mortality and morbidity of patients. For better understanding of disease, its progression and associated risk factors, further studies are essential
To describe the biological behavior of non-neoplastic and neoplastic lesions.

\section{What this study adds to the existing knowledge?}

The present study emphasis the usefulness of fiberoptic endoscopic biopsies along with histopathological examination helps in identifying the histomorphological patterns in upper gastrointestinal tract at an early stage. Early detection of these gastrointestinal tract diseases results in timely management, which also decreases the mortality and morbidity of patients.

\section{Author's contributions}

Dr. J. Margaret Theresa: Designed the study, protocol writing, manuscript preparation.

Dr. M. Lavanya: Manuscript review and guided the research work.

Dr. J. Gerard Rakesh: Manuscript review and guided the research work.

Mr. K. Sultan Basha: Data acquisition and statistical analysis.

\section{Reference}

01. Blackstone MO. Endoscopic interpretationNormal and pathologic appearances of Gastrointestinal tract. New York- Raven Press. 1984, P 13-15.

02. Gulia SP, Chaudhury M, Noorunnisa N, Balakrishnan $C D$, Balagurunathan $\mathrm{K}$. Interpretation of Upper GastroIntestinal Tract Endoscopic Mucosal Biopsies-A Study Conducted In Teaching Hospital In Puducherry, India. Int J Med Health Sci. 2012;1(3)17-24.

03. Memon F, Baloch K, Memon AA. Upper gastrointestinal endoscopic biopsy; Morphological spectrum of lesions. Professional Med J. 2015;22(12)1574-1579.

doi: [Article:https://doi.org/10.17957/TPMJ/15.3027]

04. Krishnappa R, Horakerappa MS, Mangala AK, Gouri M. A study onhistopathologic spectrum of upper gastrointestinal tract endoscopic biopsies. Int J Medical Res Health Sci. 2013;2(3)418-424. doi: [Article:https://doi.org/10.5958/j.23195886.2.3.073] 
05. Afzal S, Ahmad M, Mubarik A, Saeed F, Rafi S, Saleem N, Qur AH. Morphological spectrum of gastric lesions-Endoscopic biopsy findings. Pak Armed Forces Med J. 2006;56(2)143-149.

06. Hirachand $S$, Sthapit RR, Gurung P, Pradhanang $S$, Thapa R, Sedhai M, RegmiS. Histopathological spectrum of upper gastrointestinal endoscopic biopsies. J BP Koirala Inst Health Sci. 2018;1(1)67-74. doi:

[Article:https://doi.org/10.3126/jbpkihs.v1i1.19760]

07. Saha. Studies on Helicobacter pylori- National Institute of Cholera and Enteric Diseases. Annual Report. 2004-2005.

08. Teriaky A, Al Nasser A, McLean C, Gregor J, Yan $B$. The utility of endoscopic biopsies in patients with normal upper endoscopy. Can J Gastroenterol Hepatol. 2016;2016.

doi:

[Article:http://dx.doi.org/10.1155/2016/3026563]

09. Sgambato D, Visciola G, Ferrante E, Miranda A, Romano $L$, Tuccillo $C$, et al. Prevalence of $H$ Pylori infection in sexual partners of $\mathrm{H}$ pyloriinfected subjects- Role of gastroesophageal reflux. United Europe Gastroenterol J. 2018;6(10)1470-1476.

doi:

[Article:https://doi.org/10.1177/2050640618800628]

10. Kobayashi O, Eishi Y, Ohkusa T, Ishige. Gastric mucosal density of $\mathrm{H}$ - Pylori estimated by realtime PCR compared with results of urea breath test and histological grading. J Med Microbiol. 2002;51(4)305-311.

doi: [Article:https://doi.org/10.1099/0022-1317-514-305]

11. Shennak MM, Tarawneh MS, Al Sheik. Upper gastrointestinal diseases in symptomatic Jordanians- A prospective study. Ann Saudi Med. 1997;17(4)471-474.

doi: [Article:https://doi.org/10.5144/02564947.1997.471]

12. Nafees A Qureshi, Michael T Hallissey, John W. Fielding Outcome of indexupper gastrointestinal endoscopy in patients presenting with dysphagia in atertiary care hospital - A 10 years review. BMC Gastroenterol. 2007;7;43.

doi: [Article:https://doi.org/10.1186/1471-230X-743]
13. National Cancer Registry Programme. First All India Report 2001-2002. Vol 1. Indian Council of Medical Research- Bangalore, India. 2004

14. International Agency for Research on Cancer. Latest world cancer statistics Global cancer burden rises to 14 . 1million new cases in 2012Marked increase in breast cancers must be addressed. World Health Organization.

2013;12. Available at [Article:https://www.iarc.fr/wpcontent/uploads/2018/07/pr223_E.pdf]

15. Shin $A$, Won $Y J$, Jung $H K$, Kong $H J$, Jung $K W$, Oh $C M$, et al. Trends in incidence and survival of esophageal cancer in Korea- Analysis of the Korea Central Cancer Registry Database. J Gastroenterol Hepatol. 2018;33(12)1961-1968. doi: [Article:https://doi.org/10.1111/jgh.14289]

16. Khandelia R, Saikia M. Histopathologic Spectrum of Upper Gastrointestinal Tract Mucosal Biopsies- A Prospective Study. Int J Med Sci Clinic Invent. 2017;4(11)3314-3316.

doi:

[Article:https://doi.org/10.18535/ijmsci/v4i11.11]

17. Ozturk S, Serinsoz E, Kuzu I, Ensari A, Erden E, Kansu $A$, et al. The Sydney System in the assessment of gastritis- Inter-observer agreement. The Turkish J Gastroenterol. $2001 ; 12(1) 36-39$.

18. Fallone CA, Loo VG, Lough J, Barkun AN. Hematoxylin and eosin staining of gastric tissue for the detection of Helicobacter pylori. Helicobacter. 1997;2(1)32-35.

doi: [Article:https://doi.org/10.1111/j.15235378.1997.tb00054.x]

19. Pandya HB, Agravat HH, Patel JS, Sodagar NR. Emerging antimicrobial resistance pattern of $\mathrm{H}$ Pylori in central Gujarat. Indian J Med Microbiol. 2014;32(4)408-413.

doi: [Article:https://doi.org/10.4103/02550857.142256]

20. Singh V, Trikha B, Vaiphei K, Nain CK, Thennarasu K, Singh K. Helicobacter pyloriEvidence for spouse-to-spouse transmission. J Gastroenterol Hepatol. 1999;14(6)519-522. doi: [Article:https://doi.org/10.1046/j.14401746.1999.01908.x ]

21. Kadish SL, Kochman ML. Endoscopic diagnosis and management of gastrointestinal malignancy. Oncol. 1995;9(10)967-983. 
22. Laine L, Lewin DN, Naritoku W, Cohen $H$. Prospective comparison of H\&E, Giemsa, and Genta stains for the diagnosis of Helicobacter pylori. Gastrointest endos. 1997;45(6)463-467.

doi: [Article:https://doi.org/10.1016/S00165107(97)70174-3]

23. Morilla A, Melón $S$, ?lvarez-Argüelles $M E$, Armesto $E$, Villar $H$, de Oña $M$. Utility of normalized genome quantification of $\mathrm{H}$ Pylori in gastric mucosa using an in-house real-time polymerase chain reaction. PloS one. 2017;12(6)e0178674.

doi:

[Article:https://doi.org/10.1371/journal.pone.017867 4]

24. Hassan TM, Al-Najjar SI, Al-Zahrani IH, Alanazi FI, Alotibi MG. H Pylori chronic gastritis updated Sydney grading in relation to endoscopic findings and $\mathrm{H}$ pylori IgG antibody-diagnostic methods. J Microscop Ultrastruct. 2016;4(4)167-174.

doi:

[Article:https://doi.org/10.1016/j.jmau.2016.03.004]

25. Sheikh BA, Hamdani SM, Malik R. Histopathological spectrum of lesions of upper Gastrointestinal tract-A study of endoscopic biopsies. GJMEDPH. 2015;4(4)1-8.

26. Shepherd NA, Valori RM. The effective use of gastrointestinal histopathology-guidance for endoscopic biopsy in the gastrointestinal tract. Front Gastroenterol. 2014;5(2)84-7.

doi: [Article:http://dx.doi.org/10.1136/flgastro-2013100413]

27. Islam SM, Ahmed AM, Ahmad MS, Hafiz SA. Endoscopic and histologicDiagnosis of upper gastrointestinal lesions, Experience in a port city of Bangladesh. Chattagram Maa-O-Shishu Hospital Med College J. 2014;13(3)11-14.

doi:

[Article:https://doi.org/10.3329/cmoshmcj.v13i3.209 97]
28. Khatib WM, Demde RB, Aher VC, Patel PM. Histopathological Spectrum of Non-Malignant Lesions of Gastrointestinal Tract-An Institutional Stud. IOSR J Dent Med Sci. 2016;15(10)113116 .

29. Nwafor CC, Nwafor NN, Etuk EB, Kanu O. Histopathological spectrum of gastrointestinal lesions seen in university of uyo teaching hospital, South-South Nigeria. Ann Trop Pathol. 2019;10(1)27-33.

doi: [Article:https://doi.org/10.4103/atp.atp_40_18]

30. Khandelia R, Saikia M. Histopathologic Spectrum of Upper GastrointestinalTract Mucosal BiopsiesA Prospective Study. Int J Med Sci Clinic Invent. 2017;4(11)3314-3316.

doi:

[Article:https://doi.org/10.18535/ijmsci/v4i11.11]

31. Hussain SI, Reshi R, Akhter G, Beigh A. Clinico histopathological study ofupper gastrointestinal tract endoscopic biopsies. Int J Curr Res Rev. $2015 ; 7(16) 78-85$.

32. Thapa R, Lakhey M, Yadav PK, Kandel P, Aryal C, Subba K. Histopathologicalstudy of endoscopic biopsies. J Nepal Med Assoc. 2013;52(190)354356.

doi: [Article:https://doi.org/10.31729/jnma.2116]

33. Prasaad PR, Rao B. Histopathological spectrum of gastrointestinal lesions-anexperience in a tertiary care centre in South India. Int J Res Med Sci. 2016;4(8)3407-3412.

doi: [Article:http://dx.doi.org/10.18203/23206012.ijrms20162302]

34. Shennak MM, Tarawneh MS, Al Sheikh TM. Pattern of upper gastrointestinal disease in symptomatic Jordanians- a prospective endoscopic study of 5657 patients. Dirasat. $1998 ; 25(2) 69-81$. 